\title{
XXXIII. On the electrical origin of chemical heat
}

\section{James P. Joule Esq.}

To cite this article: James P. Joule Esq. (1843) XXXIII. On the electrical origin of chemical heat , Philosophical Magazine Series 3, 22:144, 204-208, DOI: 10.1080/14786444308636352

To link to this article: http://dx.doi.org/10.1080/14786444308636352

册 Published online: 01 Jun 2009.

Submit your article to this journal 준

Џ Article views: 7

Q View related articles $₫$ 


\section{Mr. Joule on the Electrical Origin of Chemical Heat.}

tricity may be diffused over every one of its particles, and no important part of the inductric charge be accumulated upon its under surface, yet the induction upon the earth will be as strong as if all that portion of force which is directed towards the earth were upon that surface; and the state of the earth and its tendency to discharge to the cloud sill also be as strong in the former as in the latter case. As to whether lightning-discharge begins first at the cloud or at the earth, that is a matter far more difficult to decide than is usually supposed * ; theoretical notions would lead me to expect that in most cases, perhaps in all, it begins at the earth. I am,

Royal Institution, My dear Phillips, ever yours, 4th Feb. 1843.

M. Faraday.

XXXIII. On the Electrical Origin of Chemical Heat. By James P. Joule, Esq. $\dagger$

IN a paper $\$$ which $I$ read on the 2 nd of last November before the Literary and Philosophical Society of this town, I endeavoured to account for the heat evolved by the combustion of certain bodies, on the hypothesis of its arising from resistance to the conduction of electricity between oxygen and the combustibles at the moment of their union. Taking this view of phrnomena, I showed that the heat evolved by the union of two atoms is proportional to the electromotive force of the current passing between them, in other words, to the intensity of their chemical affinity.

In that paper I gave the results of my own experiments, and I apprehended that my numbers were below the truth on account of the simplicity of my apparatus. On comparing them, however, with the experiments of Dulong, which were conducted in a manner very well calculated to prevent loss of heat, I now find that they agree so well with the results of that very accurate philosopher as to show that the method I adopted of carrying on the combustion in the inner of two glass jars, while the heat evolved was measured by water placed between them, was not unworthy of reliance. In the following table I give the results of Dulong's experiments reduced to degrees Fahrenheit acquired by a pound of water.

* Experimental Researches, Par. 1370, 1410, 1484.

$\uparrow$ Read before the British Association at Manchester, 25th June 1842; and now communicated by the Author.

$\ddagger$ Published in the Phil. Mag. S. 3. vol, xx. p. 98. 


\begin{tabular}{|c|c|c|c|c|}
\hline $\begin{array}{l}\text { Quantities converted into } \\
\text { Protoxides. }\end{array}$ & $\begin{array}{l}\text { Dulon } \mathbf{g}^{\prime} \mathbf{s} \\
\text { Results. }\end{array}$ & $\begin{array}{l}\text { My own Ex } \\
\text { periments. }\end{array}$ & $\begin{array}{l}\text { Theoret. } \\
\text { Results. }\end{array}$ & $\begin{array}{c}\text { Correct ed Theore- } \\
\text { tical Results. }\end{array}$ \\
\hline 40 grs. of Potassium.. & & $17 \cdot 6$ & $21 \cdot 47$ & \\
\hline $33 \mathrm{grs}$ of Zinc......... & 10.98 & $11 \cdot 03$ & 13.83 & $11 \cdot 01$ \\
\hline $28 \mathrm{grs}$ of Iron .......... & $9 \cdot 00$ & $9 \cdot 48$ & $12 \cdot 36$ & $8 \cdot 06$ \\
\hline 31.6 grs. of Copper ... & $5 \cdot 18$ & & $9 \cdot 97$ & 5.97 \\
\hline $1 \mathrm{gr}$. of Hydrogen ... & 8.98 & $8 \cdot 36$ & $10 \cdot 47$ & $10 \cdot 40^{*}$ \\
\hline
\end{tabular}

In the above table there is one metal, copper, of which I did not treat in my former paper; it will therefore be well to explain the manner in which the theoretical results for it were obtained.

Platinum wires were immersed in a saturated solution of the sulphate of oxide of copper. These were successively connected with the poles of voltaic arrangements consisting of various numbers of Smee's pairs in series. Using two pairs, I had neither current nor decomposition. But with three there were electrolytic effects, oxygen being evolved from the positive, and copper being deposited on the negative electrode. The ratio of current passed by three and four pairs was as nearly as possible $1: 4$. Therefore $2 \frac{2}{3}$ pairs are equal to the resistance to electrolysis of sulphate of oxide of copper.

Now if I calculate, as I did in my former paper for zinc, iron, and hydrogen, I must argue that electricity equal in intensity to that of $2 \frac{2}{3}$ pairs passes between oxygen and copper when they unite by combustion. But one pair of Smee's battery can produce electricity of such intensity that a degree $\dagger$ of it will evolve $3^{\circ} \cdot 74$ of heat, and multiplying by $2 \frac{2}{3}$ we have $9^{\circ} \cdot 97$, the quantity of heat which is evolved by a degree of electricity of $2 \frac{2}{3}$ times that intensity; $9^{\circ} .97$ is therefore the theoretical result, if we suppose that the intensity required to overcome the resistance to electrolysis of sulphate of oxide of copper is equal to the intensity of current arising from the union of oxygen and copper in combustion.

There is, however, since the experiments of Daniell, reason to think that this is not the case, but that part of the intensity of a current engaged in electrolyzing these compound bodies, is used in separating the acid from the base prior to or (according to that philosopher's view) simultaneously with the decomposition of the latter. Unfortunately we cannot bring forward a direct experiment in proof of this fact, inasmuch as

* I now find that Prof. Daniell has proved the remarkable fact, that during the electrolysis of dilute sulphuric acid one quarter of an equivalent of acid goes along with the oxygen to the positive electrode. According to this the corrected theoretical result is 10.47 ; one quarter of the heat evolved by the union of water and sulphuric acid equal about $9 \cdot 47$.

$+\mathrm{My}$ degree of electricity is the quantity necessary to electrolyze an equivalent expressed in grains, as nine grains of water, \&c. 


\section{$206 \mathrm{Mr}$. Joule on the Electrical Origin of Chemical Heat.}

the oxides* are by themselves, and at common temperatures, non-conductors of voltaic electricity, and therefore refuse to yield up their elements. But if on the principles of the theory we argue that the heat evolved on the combination of one equivalent with another is a measure of the intensity of the electric current passing between them at the time, we shall have the means of eliminating the electromotive force employed otherwise than in separating the elements of the oxides.

I suppose that there are three forces in operation, of which two are against, and one is for, a current engaged in electrolyzing the solution of the sulphate of a metallic oxide. The first two are the affinity of the elements of the oxide, and that of the oxide for sulphuric acid; and the third, which is in a contrary direction to the two others and generally less than either, is the affinity of water for sulphuric acid. We eliminate the two latter forces as follows:-

1st. For Zinc. - I find that 41 grs., or an equivalent of oxide of zinc, evolves $2^{\circ} .82$ when dissolved in dilute sulphuric acid. This, which is the quantity of heat due to the intensity of current resulting from the difference of the affinities of sulphuric acid for the oxides of zinc and hydrogen, leaves, when subtracted from $13^{\circ} .83,11^{\circ} .01$, the corrected theoretical result, which $I$ have given in the th column of the table.

2nd. For Iron.-The black oxide is dissolved with such difficulty by dilute sulphuric acid that the heat thereby evolved cannot be accurately measured. However, the dissolution of the hydrate is easily effected, the quantity of heat generated thereby being, per equivalent, $2^{\circ} \cdot 74$. But we probably arrive nearer the truth by subtracting from the heat evolved by the dissolution of iron in dilute sulphuric acid, that portion which is due to the oxidation of the iron. In this way I have $5^{\circ} \cdot 2-0^{\circ} \cdot 9=4^{\circ} \cdot 3$, the quantity due to the solution of protoxide of irou in dilute sulphuric acid. This, when subtracted from $12^{\circ} \cdot 36$, leaves $8^{\circ} \cdot 06$, the corrected result of theory.

3rd. For Copper. - The protoxide of copper does not dissolve readily in dilute sulphuric acid. Nevertheless by keeping the temperature of the surrounding atmosphere equal to that of the liquid, I obtained, per equivalent of oxide, $4^{\circ} 0$, a result which may, I think, be relied on. Subtracting this from $9^{\circ} \cdot 97$, we obtain $5^{\circ} \cdot 97$.

4th. For Hydrogen, little correction is needed †. 'The liquid used in the experiments made to ascertain the resistance to electrolysis of water was mixed with a small quantity only

* I find that pure water is not at all decomposed by ten pairs of Smee's battery in series, the current being thereby almost if not quite cut off.

$\uparrow$ On this question I now refer to note * appended to page 205 . 
of sulphuric acid. Consequently there were plenty of atoms of water either uncombined, or only slightly attached to the acid, prepared to give up their elements to the current with little or no additional resistance in consequence of its presence.

By inspecting the table it will be seen that these corrected theoretical results agree very well with the experiments of Dulong and myself. They accord accurately in the case of zinc. Iron gives results which are not equally satisfactory. But we must remember that it is converted by combustion into the magnetic oxide, and that a correction ought therefore to be applied on account of heat evolved by the union of protoxide with oxygen, which it is very difficult to prevent entirely. Potassium gives theoretical and experimental results as nearly alike as can, I think, be expected, considering the complicated process* by which the former were obtained, and the practical difficulty of the latter. In the case of hydrogen we might have anticipated that theory would exceed experiment ; for the resistance to electrolysis of water appears generally greater than it really is, on account of the peculiar state which the platinum evolving hydrogen is apt to assume, which has, of course, the effect of increasing the theoretical value.

Besides the corrections to the theoretical results which I have supplied, I thought that there might be a slight one needed on account of $l i g h t$ which is evolved in such abundance in some instances of combustion. It was of importance to ascertain whether in the evolution of light an equivalent of heat was absorbed. With this view I have made an extensive series of experiments with the voltaic apparatus, comparing the heat evolved when no light was exhibited, with that evolved when the conducting wire was ignited to whiteness. The mean of twelve experiments showed that the heat evolved by a certain quantity of wire immersed in water is, for a given quantity of current and a given length of time, $24^{\circ} \cdot 75$; and the mean of sixteen experiments, in which a platinum wire inclosed in a glass tube surrounded with water was ignited so as to give out a quantity of light equal to that arising from a common tallow candle, gave $24^{\circ} \cdot 4$ as the quantity of heat due in this latter case to similar circumstances of resistance and quantity of current. These experiments seem to indicate that heat is lost when light is evolved, but in so slight a degree that my experiments on the heat of combustion need not be corrected for it. Dulong's experiments were performed in a box of copper, which being opake would entirely obviate this source of error.

I conceive that the correctness of the idea, entertained, I

* Phil. Mag. S. 3. vol. xx. p. 109 (49). 


\section{Sir Graves C. Haughton's Experiments in Electricity.}

believe, by Davy, and afterwards more explicitly mentioned by Berzelius, that the heat of combustion is an electrical phænomenon, is now rendered sufficiently evident. We have also shown that the heat arises from resistance to the conduction of electricity between the atoms of combustibles and oxygen at the moment of their union. Of the nature of this resistance we are still ignorant.

Some time ago I commenced an investigation on the heat arising from the union of sulphuric acid with potash, soda, and ammonia. This inquiry is more difficult than I expected, and my experiments are not yet sufficiently complete to lay before the British Association. In a future paper I hope to extend my inquiry, and also to show the relation of latent heat to electrical intensity.

\section{Experiments in Electricity. By Sir Graves C. Haughton, K.H., F.R.S. \\ To the Editor of the Philosophical Magazine and Journal. Sir,}

A $\mathrm{S}$ every phænomenon connected with electricity must be interesting to the scientific world, whether it brings to light a new principle or merely confirms one that has been already established, I have thought that the following experiments might prove acceptable to your readers.

If a needle of any of the malleable metals, or of other substances, such as wood, ivory, quill and straw, or even of glass or sealing-wax, be placed in a galvanometer of the simplest form, and one end of the wire be fixed in metallic contact to the hook of the prime conductor of an electrifying machine, less than a quarter of a revolution of the handle will, if the machine be in good working order, cause the needle to stand at an angle of $90^{\circ}$. If the proper needle of the galvanometer be employed instead of one of the foregoing, it will place itself at an angle of from $75^{\circ}$ to $80^{\circ}$, and will preserve that position as long as the machine is kept in operation. The needles with which these experiments were tried varied in length from three inches to five-eighths of an inch. The galvanometer stood at first simply on a mahogany table, but the results were not certain with every kind of needle, owing apparently to their faulty construction; when, however, it was placed on a good insulator the experiments never failed. It is worthy of remark, that whenever the state of the atmosphere was unfavourable to the working of the machine, which has been uniformly the case during the present month, in consequence of 